\title{
Constructivist practices through guided discovery approach: The effect on students' cognitive achievement in Nigerian senior secondary school physics
}

\author{
Akinyemi Olufunminiyi Akinbobola ${ }^{a}$ and Folashade Afolabi ${ }^{b, 1}$ \\ ${ }^{a}$ Department of Science Education, University of Uyo, Uyo, Nigeria \\ ${ }^{\mathrm{b}}$ Department of Teacher Education, University of Ibadan, Ibadan, Nigeria
}

\begin{abstract}
The study investigated constructivist practices through guided discovery approach and the effect on students' cognitive achievement in Nigerian senior secondary school Physics. The study adopted pretest-posttest control group design. A criterion sampling technique was used to select six schools out of nine schools that met the criteria. A total of 278 students took part in the study; this was made up of 141 male students and 137 female students in their respective intact classes. Physic Achievement Test (PAT) with the internal consistency of 0.77 using Kuder Richardson formula 21 was the instrument used in collecting data. The data were analysed using Analysis of Covariance (ANCOVA) and t-test. The results showed that guided discovery approaches was the most effective in facilitating students' achievement in physics after being taught using a pictorial organizer. This was followed by demonstration while expository was found to be the least effective. Also, there exists no significant difference in the achievement of male and female physics students taught with guided discovery, demonstration and expository teaching approaches and corresponding exposure to a pictorial organizer. It is recommended that physics teachers should endeavour to use constructivist practices through guided discovery approach in order to engage students in problem solving activities, independent learning, critical thinking and understanding, and creative learning, rather than in rote learning and memorization.
\end{abstract}

Key words: Constructivist, Guided Discovery, Students' Cognitive Achievement, Physics

\section{Introduction}

The challenge in teaching is to create experiences that involve the student and support his own thinking explanation, evaluation, communication and application of the scientific models needed to make sense of these experiences. Hence, constructivism is a theory that suggests that learners construct knowledge out of their experiences which is associated with pedagogical approaches that promote learning by doing or active learning. (Afolabi \& Akinbobola, 2009). Constructivist teaching focus an independent learning, creativity, critical thinking and problem solving. Constructivist teaching is based on the fact that skills and knowledge acquisition are not by passive receiving of information and rote learning but involve active participation of the learners through knowledge construction, hands-on and minds-on activities (Akinbobola \& Ado, 2007).

Teacher roles in Constructivist teaching is to serve as facilitor of learning in which students are encouraged to be responsible, autonomous and construct their own understanding of each of the scientific concept. Hence, the activities are learner-centred, democratic and interactive. In constructivist classroom, the teacher facilitates and provides students with experiences that allow them to use the science process skills such as observing, measuring, classifying, communicating, inferring, using number, using space/time relationship, questioning, controlling and manipulating variable, hypothesizing, defining operationally, formulating models, designing experiment and interpreting data.

According to Inyang (1993), activity based science teaching allows students to explore their environment and discover nature. As such, a lot of inquiry prevails in the classroom, with the teacher acting as a motivator, getting from point-to-point to guide the learning of students and help them overcome difficulties. The teachers performs the role of a resource person who guides the learners to sources of information. 
Nwagbo (1999) explains that in the guided discovery mode which is an example of constructivist learning, is an approach to enquiry. On the other hand, the teacher provides illustrative materials for students to study on their own. Leading questions are then asked by the teacher to enable students think and provide conclusion through the adoption of the processes of sciences. Nwagbo believes that if the learner is allowed to discover relationships and methods of solution by himself, make his own generalizations and draw conclusions from them, he may then better prepared to make wider applications of the material learned. According to Ugwuanyi (1998), a learner is active in discovery leaning, and provides for individual differences as well as makes the process of learning to be self-sequenced, goal directed, with the goal perceived and the pace self-determined.

Demonstration is a teaching approach that links explanation with practice. Berkey (1995) explains that a good demonstration exercise helps students to understand the lesson very clearly, since they combine the senses of sight, hearing and touching while learning. That is, it is a technique of teaching concepts, principles or real things by combining oral explanation with the handling or manipulation of real things. According to Urevbu (1990), demonstration is an approach of instruction which combines presentation and investigation. The purpose behind this approach of instruction may be outlined as follows:

- Apparatus is introduced to the student in such a way that he is able to understand its uses and limitations.

- The student is encouraged to adopt by imitating the correct methods of use of the apparatus.

- Time is saved and the number of teaching staff required to provide individual laboratory instruction is reduced.

- The student is shown experiments which because of the danger, cost or complexity involved, he could not perform in the laboratory.

Expository teaching merely emphasizes presenting ideas and information meaningfully and effectively so that the learner can derive other meanings from what he is presented with. Expository teaching is sometimes called deductive teaching because the teacher often begins with a definition of the concepts or principles illustrate them and unfolds their implications. Factual information is most easily learned if it is organized and sequenced logically. Hence, the contents of material must be presented in a logical order, moving from generic to specific concepts, so that learners can form cognitive structures and encode new information. The expository approach is a teacher-centred, student-peripheral teaching approach in which the teacher delivers a pre-planned lesson to the students with or without the use of instructional materials.

Gbamanja (1991) observes that in using this approach, the teacher talks about science while the students read about science. However, the modern expository approach involves more than talking and reading about science, for it allows some interaction between the teacher and the students in terms of asking and being asked questions on the topic of discussion.

A pictorial organizer is a visual and graphic display that depicts the relationships between facts terms and /or ideas within a learning task. Pictorial organizer is a form of advance organizer and are also sometimes referred to as knowledge maps, concepts maps, cognitive organizers or concept diagrams. According to Mayer (2003), the effects of advance organizers should be most visible for test that involve creative problem solving, because the advance organizer allows the learner to organize the material into a familiar structure. New information about a concept is filled into an existing framework of categories called "Schemes" that contain specific information about a concept. So, when prior knowledge is retrieved this schema provides a framework on which to attach new knowledge. If no previous knowledge is available, advance organizers are used to give knowledge to the students in order for this framework to be followed and new information retained for recall and transfer (Bromley, Irwin-Devitis \& Modlo, 1995). 


\section{Statement of the Problem}

For more than a decade now, the different instructional strategies employed in teaching physics have not improved students' achievement in the subject to any appreciable extent. This mean that the most desire scientific and technological application of physics cannot be sustained. The implication is that the teaching of physics does not lead to students' understanding of concepts, functionality and application of its ideas. Hence, the need to find pedagogic approaches that promote active learning. What will be the effect of teaching approaches (guided discovery, demonstration and expository) on students' cognitive achievement in Physics?

\section{Purpose of the Study}

The study is designed to achieve the following specific objectives:

1. To investigate the effect of teaching approaches ( guided discovery, demonstration and expository) on students' cognitive achievement in physics after being taught using a pictorial organizer

2. To determine the effect of gender ( Male and female) on students' cognitive achievement in physics after being taught with (i) guided discovery (ii) demonstration (iii) expository teaching approaches and corresponding exposure to a pictorial organizer.

\section{Hypotheses}

The Following null hypotheses were formulated and tested at 0.05 level of significance.

1. here is no significant effect of teaching approaches (guided discovery, demonstration and expository) on students' cognitive achievement in Physics after being taught using a pictorial organizer.

2.There is no significant effect of gender (male and female) on students' cognitive achievement in physics taughts with (i) guided discovery (ii) demonstration (iii) expository approaches and corresponding exposure to a pictorial organizer.

\section{Method}

The research design adopted for this study was a non-randomize pretest-posttest control group. The population for the study was made up of all the senior secondary two (SS2) physics students in the 12 co-educational secondary schools in Ife Central Local Government Area of Osun State. The size of the population was 852 senior secondary two (SS2) physics students. A total of 278 students took part in the study; this was made of 141 male students and 137 female students. Purposive sampling technique was used to select schools from the target population. The criteria are:

1. Schools that have well equipped and functional physics laboratories

2. Schools that are currently presenting candidates for the Senior Secondary School certificate Examination (SSSCE) and have at least one professional graduate physics teacher with at least three years of teaching experience.

3. School in which the concept of heat energy transfer has not been taught already.

Nine schools met the above criteria six schools among those that met the criteria were selected by balloting. The schools were randomly assigned to treatment and control groups. One intact class was randomly selected in each school.

The researchers made instrument, physics Achievement Test (Pat) comprised of 50multiple choice items in the concept of heat energy transfer was used in collecting the data for the study. Each items had four option with only on e correct answer and the correct answer was score 2 marks. The Pat was validated by two physics education and their comment and corrections were incorporate into the final form of the instrument. The difficulty and discrimination indices of PAT items were 0.62 and 0.52 respectively. The PAT trial tested with 40 subjects who were not part of the main study but who were found to be equivalent in all 
respects to the students used for the study. A reliability coefficient of 0.77 was obtained using Kuder Richardson formula 21.

The pictorial organizer package was developed by the researcher and consisted of various charts, pictures and maps related to the concept of energy in term of forms of energy, source of energy, conversions of energy and application of energy conversion, which served as subsumer for the learning of heat transfer.

The variables of teacher quality were controlled by using research assistants who were the physics teachers in each school to teach each group. Detailed instructions with lesson plan on the concept of heat energy transfer were given to the researcher assistants during the training that was conducted for them in one week. Pre-test was administered to both the experimental and control groups and the results were used as covariate measures in order to take care of possible initial differences in groups. Two days after the administration of the pretest, pictorial organizer was introduced to the two groups (experimental and control groups) for Ihr 20 minutes (double period) in each class by the research assistants.

The teaching of the concept, heat energy transfer was done by the research assistants in each school from a well-articulated lesson package developed by the researcher for six (6) weeks. The lesson packages prepared by the researcher were used in order to standardize the concept that was taught by research assistants. The experimental group 1 was taught using guided discovery while the experimental group 2 was taught using demonstration. The control group was taught using expository teaching method. Immediate after the teaching of the concept of heat energy transfer, posttest was administered to the experimental and control group. The data obtained were analysis using t-test and analysis of covariance. All the hypotheses were tested at 0.05 level of significance.

\section{Procedure}

The pictorial organizer was initially introduced to all the groups before treatment. This is to present students with context and conceptual frameworks that help students to arrange, integrate and retain material, other than specify content and detail. If no previous knowledge is available, the pictorial organizer will provide a frame work on which to attach knowledge. Learning is interactive, building on what the students already know. The experimental group I was taught with guided discovery. Using this approach, the teacher provides illustrative materials for students to study on their own. Leading questions are then asked by the teacher to enable students think and provide conclusion through the adoption of the processes of science. The teachers guide the students and help them to construct their own knowledge. The experimental group 2 was taught demonstration. In this approach, the teacher alerts the class of the purpose of the demonstration and explains the step-by step operations that will be involved. Thereafter, he carefully carries out the demonstration and describes every step and action while students watch. The students are encouraged to adopt by imitation of the correct methods of the use of the apparatus. The experimental group 3 (control group) was taught with expository. In this approach, the teacher involves in the selection, organization and translation of subjectmatter in a developmentally appropriate manner. The teaching is deductive because the teacher often begins with a definition of the concepts or principles, illustrates them and unfolds their implications. The contents of material are presented in a logical order, moving from generic to specific concepts.

\section{Results}

As shown in Table 1, it was observed that the mean gain scores of male and female students taught with guided discovery were greater than the mean gain scores of male and female students taught with demonstration which in turn were greater than the mean gain score of male and female students taught with expository after being exposed to a pictorial organizer. It was however observed that the mean gain score of male students (40.64) was greater than the mean gain score of female students (39.37). 
Table 1. Descriptive of pre-test, post-test and the mean gain scores

\begin{tabular}{|c|c|c|c|c|c|c|c|}
\hline \multirow[t]{2}{*}{ Gender } & \multirow[t]{2}{*}{ Teaching Approaches } & \multirow[t]{2}{*}{$\mathrm{N}$} & \multicolumn{2}{|c|}{ Pretest scores } & \multicolumn{2}{|c|}{ Posttest scores } & \multirow{2}{*}{$\begin{array}{l}\text { Mean } \\
\text { Gain } \\
\text { Score }\end{array}$} \\
\hline & & & $\bar{X}$ & S.D & $\bar{X}$ & S.D & \\
\hline \multirow[t]{3}{*}{ Male } & Discovery & 47 & 29.23 & 7.51 & 77.87 & 9.13 & 48.64 \\
\hline & Demonstration & 49 & 28.74 & 7.92 & 69.80 & 10.40 & 41.06 \\
\hline & Expository & 45 & 28.18 & 7.54 & 60.00 & 7.30 & 31.82 \\
\hline Total & & 141 & 28.72 & 7.62 & 69.36 & 11.57 & 40.64 \\
\hline \multirow[t]{3}{*}{ Female } & Discovery & 47 & 29.87 & 7.53 & 77.58 & 9.02 & 47.71 \\
\hline & expository & 44 & 29.82 & 7.32 & 68.64 & 10.10 & 38.82 \\
\hline & & 46 & 28.17 & 6.89 & 59.57 & 8.07 & 31.40 \\
\hline Total & & 137 & 29.29 & 7.24 & 68.66 & 11.70 & 39.37 \\
\hline
\end{tabular}

\section{Hypothesis Testing}

\section{Hypothesis One}

There is no significant effect of teaching approaches (guided discovery, demonstration and expository)0 on students' cognitive achievement in physics after being using a pictorial organizer.

The analysis is as shown in Table 2.

Table 2. One way Analysis of Covariance (ANCOVA) of post test scores of students taught with guided discovery, demonstration and expository using pretest scores as covariates.

\begin{tabular}{|c|c|c|c|c|c|c|c|}
\hline $\begin{array}{l}\text { Source } \\
\text { Variation }\end{array}$ & of & Sum of Squares & $\overline{\mathrm{Df}}$ & $\begin{array}{l}\text { Mean } \\
\text { Square }\end{array}$ & F-cal & F-critica & Decision at $\mathrm{p}<0.05$ \\
\hline Pretest & & 18328.76 & 1 & 18328.76 & 775.44 & 3.89 & $*$ \\
\hline Main effect & & 12560.77 & 2 & 6280.38 & 265.71 & 3.04 & $*$ \\
\hline Explained & & 30889.53 & 3 & 10296.51 & 435.62 & 2.65 & * \\
\hline Residual & & 6476.42 & 274 & 23.64 & & & \\
\hline Total & & 37365.94 & 277 & 134.90 & & & \\
\hline
\end{tabular}

- = Significant at $\mathrm{p}<0.05$ alpha level

Table 2 shows that the teaching approaches main effect was significant at $\mathrm{p}<.05$. The calculated F-value of 265.71 is greater than the critical F-value of 3.04. Therefore, the null hypothesis stating a non-significant effect of teaching approaches (guided discovery demonstration and expository) on students' achievement in physics after being taught using a pictorial organizer was rejected. This implies that the three types of teaching approaches (guided discovery, demonstration and expository) differ significantly in their enhancement of the achievement of physics students after being taught using a pictorial organizer. Consequent upon the observed difference in the teaching approaches, Multiple Classification Analysis (MCA) was considered to determine the index of relationship and also to determine the variance of the dependent variable (achievement) in physics that is attributable to the influence of the independent variable (teaching approaches) as shown in Table 3.

As shown from Table 3, the teaching approaches (guided discovery, demonstration and expository) have an index of relationship of $0.34\left(0.58^{2}\right)$, hence the observed relationship in favour of teaching approaches, shows that the teaching approaches have a significant relationship 0.34 (Beta value of $\left(0.58^{2}\right)$ with achievement of students in physics. Table 3 also shows a multiple regression index (R) of 0.91 with a multiple regression squared index $\left(\mathrm{R}^{2}\right)$ of 0.83 . This implies that $83 \%$ of the total variance in the achievement of students in physics is attributable to the influence of teaching approaches after being exposed to a pictorial organizer. 
Table 3. Multiple Classification Analysis (MCA) of the posttest scores of students taught with guide discovery, demonstration and expository teaching approaches.

\begin{tabular}{|c|c|c|c|c|c|}
\hline Grand Mean $=69.01$ & $\mathrm{~N}$ & Unadjusted & & $\begin{array}{l}\text { Adjus } \\
\text { Varial }\end{array}$ & $\begin{array}{l}\text { ependent } \\
\text { ariates }\end{array}$ \\
\hline Variable + Category & & Dev'n & Eta & Dev'n & Beta \\
\hline TEACHING APPRROACHES & & & 0.63 & & 0.58 \\
\hline Guided Discovery & 94 & 8.71 & & 8.14 & \\
\hline Demonstration & 93 & 0.23 & & -0.02 & \\
\hline Expository & 91 & -9.23 & & -8.39 & \\
\hline Multiple R. $=0.91$ & & & & & \\
\hline Multiple R. Squared $=0.83$ & & & & & \\
\hline
\end{tabular}

To find the direction of significance under investigation, the posttest scores were subjected to Scheffe Multiple Comparison test for a post hoc analysis as shown in Table 4.

Table 4. Result of Scheffe's post hoc test for multiple comparison of teaching approaches on students' achievement in physics

\begin{tabular}{lllllll}
\hline \multicolumn{2}{l}{ Dependent Variables: POST TEST SCORES } & & & \\
\hline $\begin{array}{l}\text { (1) Teaching } \\
\text { Approaches }\end{array}$ & $\begin{array}{l}\text { (J)Teaching } \\
\text { Approaches }\end{array}$ & $\begin{array}{l}\text { Mean } \\
\text { Difference } \\
\text { (I-J) }\end{array}$ & Std. Error & Sig. & $\begin{array}{l}95 \% \text { Confidence } \\
\text { Lower Bound }\end{array}$ & $\begin{array}{l}\text { Interval } \\
\text { Upper } \\
\text { Bound }\end{array}$ \\
\hline GDY & DEM & $8.48^{*}$ & 1.322 & 0.000 & 5.22 & 11.73 \\
& EXP & $17.94^{*}$ & 1.330 & 0.000 & 14.67 & 21.22 \\
DEM & GDY & $-8.48^{*}$ & 1.322 & 0.000 & -11.73 & -5.22 \\
& EXP & $9.47^{*}$ & 1.333 & 0.000 & 6.19 & 12.75 \\
EXP & GDY & $-17.94^{*}$ & 1.330 & 0.000 & -21.22 & -14.67 \\
& DEM & $-9.47^{*}$ & 1.333 & 0.000 & 14.67 & 21.22 \\
\hline
\end{tabular}

- The mean difference is significant at the 0.05 level

Where: GDY = Guided discovery, DEM = Demonstration, EXP $=$ Expository

As shown in Table 4, the mean difference between GDY and DEM was 8.48, between GDY and EXP was 17.94, and between DEM and EXP was 9.47. This implies that guided discovery is the most effective in facilitating students' achievement in Physics after being exposed to a pictorial organizer. This is followed by demonstration while expository is seen to be the least effective in facilitating students' achievement in physics after being exposed to a pictorial organizer.

\section{Hypothesis Two}

There is no significant effect of gender (male and female) on students' achievement in physics taught with (i) guided discovery (ii) demonstration (iii) expository teaching approaches and corresponding exposure to a pictorial organizer.

$\mathrm{H}_{0} 2$ (i) There is no significant effect of gender (male and female) on students' achievement in physics taught with guided discovery and corresponding exposure to a pictorial organizer. The analysis is as shown in Table 5.

Table 5. t-test comparison of posttest mean scores of male and female students taught with guided discovery

\begin{tabular}{llllllll}
\hline Gender & N & $\overline{\boldsymbol{X}}$ & S.D. & DF & t-cal. & t-critical & Decision at $\mathrm{p}<0.05$ \\
\hline Male & 47 & 77.87 & 9.13 & 0.16 & 92 & 1.98 & NS \\
\hline Female & 47 & 77.57 & 9.02 & & & & \\
\hline
\end{tabular}

NS $=$ Not significant at $\mathrm{P}<0.05$ alpha level

The analysis in Table 5, shows that the calculated t-value of 0.16 is less than the critical tvalue of 1.98 at $\mathrm{P}<.05$. Therefore, the null hypothesis stating a non significant effect of gender (male and female) on students' achievement in physics taught with guided discovery and corresponding exposure to a pictorial organizer was retained. This implies that gender does not significantly influence students' achievement in physics when the students are taught with guided discovery and corresponding exposure to a pictorial organizer. 
$\mathrm{H}_{0} 2$ (ii) There is no significant effect of gender (male and female) on students' achievement in physics taught with demonstration and corresponding exposure to a pictorial organizer.

Table 6. t-test comparison of posttest mean scores of male and female students taught with demonstration

\begin{tabular}{lllccccc}
\hline Gender & $\mathrm{N}$ & $\bar{X}$ & S.D. & DF & t-cal. & t-critical & Decision at $\mathrm{p}<0.05$ \\
\hline Male & 49 & 69.80 & 10.40 & 91 & 0.55 & 1.98 & N.S \\
Female & 44 & 68.64 & 10.10 & 8 & & & \\
\hline
\end{tabular}

$\mathrm{NS}=$ Not significant at $\mathrm{p}<0.05$ alpha level

The analysis in Table 6 , shows that the calcualated t-val;ue of 0.55 is less than the critical $\mathrm{t}$-value of 1.98 at $\mathrm{p}<.05$. Therefore, the null hypothesis stating a non significant effect of gender (male and female) on students' achievement in physics taauight with demonstration and corresponding exposure to a pictorical organizers was retained. This implies that gender does not significantly influence students' achievement in physics when the students are taught with demonstration and corresponding exposure to a pictorial organizer.

$\mathrm{H}_{0} 2$ (iii) There is no significant effect of gender (male and female) on students' achievement in physics taught with expository and corresponding exposure to a pictorial organizer.

The analysis is as shown in Table 7.

Table 7. t-test comparison of achievement mean scores of male and female students taught with expository

\begin{tabular}{llllllll}
\hline Gender & $\mathrm{N}$ & $\bar{X}$ & S.D. & DF & t-cal. & t-critical & Decision at $\mathrm{p}<.05$ \\
\hline Male & 45 & 60.00 & 7.30 & 89 & 0.27 & 1.98 & N.S \\
Female & 46 & 59.57 & 8.07 & 8 & & & \\
\hline
\end{tabular}

NS $=$ Not significant at $\mathrm{P}<0.05$ alpha level.

The analysis in Table 7 shows that the calculated t-value of 0.27 is less than the critical tvalue of 1.98 at $\mathrm{P}<.05$. Therefore, the null hypothesis stating a non significant effect of gender (male and female) on students' achievement in physics taught with expository and corresponding exposure to a pictorial organizer was retained. This implies that gender does not significantly influence students' achievement in physics when the students are taught with expository and corresponding exposure to a pictorial organizer.

\section{Discussion of Results}

The result of hypothesis one as shown in Table 2 indicated that a significant difference was found to exist in the achievement of students in physics taught with guided discovery, demonstration and expository after being exposed to a pictorial organizer. Multiple Classification Analysis (MCA) as shown in Table 3 indicated that $83 \%$ of the total variance in the achievement of students in physics is attributed to the influence of teaching approaches after being exposed to pictorial organizer. The Scheffe's post hoc analysis as shown in Table 4 indicated that guided discovery was the most effective in facilitating students' achievement in Physics after being exposed to a pictorial organizer. This was followed by demonstration while expository was seen to be the least effective.

The findings might be due to the stability and clarity of the anchoring ideas that the pictorial organizer provided in the cognitive structure of the physics students and it seemed to make students to remember more conceptual ideals and were able to relate the test to prior knowledge. The findings tally with the results of Onwioduokit \& Akinbobola (2005) that a pictorial organizer is one of the most effective in facilitating students' achievement and retention of materials taught in physics among different types of advance organizers. Also, the constructivist view of learning point towards a numbers of different teaching practices. It usually means encouraging students to use active techniques (guided discovery and demonstration) to create more knowledge and then to reflect on and talk about what they are doing and how their understanding is changing. The teacher makes sure he understands the 
students' preexisting conceptions (through pictorial organizer), and guides the activity to address them and then build on them.

Constructivist teaching is based on the facts that learning occurs as learners are actively involved in a process of meaningful and knowledge construction rather than passively receiving information. Learners are the makers of their own learning. Hence, it fosters independent learning, creative thinking and motivates learning. This research study supports those of earlier studies of Nicholas (1996), Kersh (1998), Omwirhiren (2002), and Akinbobola (2006) that the guided discovery approach was effective in enhancing the achievement and retention of students in science subjects. This finding might be due to the fact that guided discovery has the benefit of increasing intellectual potency by enhancing the learner's ability to organize and classify information. Information imbibed through guided discovery becomes firmly embedded in the cognitive structure of the learner thereby facilitating retrieval.

The study is in agreement with position of Onyejiaku (1987) who opined that in the learning process involving reacting, doing and experiencing such as demonstration, information is better registered because the hearer sees the instructor demonstration strategy over expository strategy.

The results of the investigation as shown in Table 5,6 and 7 indicated an insignificant effect existing between the achievement of male and female physics students taught with guided discovery, demonstration and expository teaching approaches and corresponding exposure to a pictorial organizer. This may be so because any good teaching approach adopted in the teaching of physics does not discriminate between the sexes. Also, applying appropriate teaching approaches. Also, applying appropriate teaching approaches can help both male and female students learn and remember facts, apply skill, comprehend concepts, analyze and synthesize principles which are cognitive objective for physics education. Also, the enthusiasm exhibited by both male and female students who showed equal zeal when they were taught using a pictorial organizer may have led to equal performance at given tasks. This might be due to the fact that both male and female students interact with each other freely in groups and have led to increasing the depth of understanding, enhancing motivation, developing positive attitude toward later use of material presented in the course, develop problem solving skills and generating greater involvement of both male and female students with the concept.

The result is also consistent with the findings of Leinhardt, Seewald and Engelra (1999), Akinbobola (2006) Akinbobola (2008), and Afolabi and Aklinbobola (2009) that show no significance difference in the mean performance between boys and girls in the manipulation of the same instructional materials as well as in their rate of contribution and class participation. He noted that every child, both male and female must be given the opportunity to display his/her manipulate ability as fully as possible, be he quick or slow, deep or superficial in thinking, once they are taught with the same teaching approach. This is because a good performance of student depends on his interest as well as the techniques used by the teacher and the types of instructional materials involved, in that two students taught under different conditions normally perform differently.

\section{Conclusion and Implications}

A pictorial organizer enhances students' achievement in physics. Guided discovery is the most effective in facilitating students' achievement in physics after being taught using a pictorial organizer. This is followed by demonstration while expository is found to be the least effective. Also, there exists no significant difference in the achievement of male and female physics students taught with guided discovery, demonstration and expository teaching approaches and corresponding exposure to a pictorial organizer.

The findings of this investigation have implications for improvement of science and technology in Nigeria. The guided discovery approach has been found in this study to be the most effective in the achievement of students in physics. Therefore, the sustenance of students' interest in science and technology can be achieved by the adoption of the guided discovery approach of instruction which, if well planned, can encourage and motivate the student to practice and apply the scientific knowledge gained to new situation by making use of the 
process skills of science. This could lead to the acquisition and development of technology in the country. Through self-discovery, students will be able to develop more positive attitude towards learning skills and also, it will enhance learning outcomes through hands-on and minds-on activities.

\section{Recommendations}

Based on the results of the study, the following recommendations were made:

1. Physics teachers should endeavor to use constructivist practices through guided discovery approach in order to engage students in thinking understanding and creative learning, rather than on rote learning and memorization.

2. Federal, State and Local Government should upgrade the infrastructures and equip laboratories in order for the students to be actively involved in their learning.

3. Physics teachers should always improvise simple basic laboratory material for effective use in hands-on strategies, in the absence of standard laboratory materials.

4. Physics students should be engaged in laboratory activities for meaningful acquisition of scientific knowledge, processes and ethics.

5. Physics teachers should make all their lessons problem-oriented, because students always show interest when they are faced with a puzzle.

6. Curriculum planners for senior secondary school physics should as a matter of priority incorporate pictorial organizer in curriculum development and physics teachers should explore the use of pictorial organizers in teaching various concepts at senior secondary school level.

\section{References}

Afolabi, F \& Akinbobola, A.O. (2009). Constructivist problem based learning technique and the academic achievement of physics student with low ability level in Nigerian secondary schools. Eurasian Journal of Physics and Chemistry Education, 1(1), 45-51.

Akinbobola, A.O. (2006). Effects of teaching methods and study habits on students' achievement in senior secondary school physics, using a pictorial organizer. Unpublished Ph.D dissertation, University of Uyo, Uyo, Nigeria.

Akinbobola, A.O. (2008). Facilitating Nigerian physics students' attitude towards the concept of heat energy. Scientia Paedagogica Experimentalis, XLV(2), 353-366.

Akinbobola, A.O. \& Ado, I.B. (2007). Hands-on and minds-on strategies for teaching of force: Guided discovery approach. In E. Udo, U. Uyoata, N.E.U. Inyang, H.Yero, \& G.Bello (Eds.), Hands-on and minds-on strategies in the teaching of force. Proceeding of the Science Teachers Association of Nigeria (STAN) primary science workshop. Uyo: Afahaide \& Bros. Printing \& Publishing Co. 65-72.

Berkey, A.L. (1995). Selecting teaching methods and materials. The Agricultural Educational Magazine, 47(9), 199.

Bromley, K. Irwin-Devitis, A. \& Modlo, M. (1995). Graphic Organizers. New York: Scholastic Professional Books.

Gbamanja, S.P.T. (1991). Constraints on the successful implementation of the science progamme at the senior secondary school level in Nigeria. Onitsha: African Feb. Publishers Ltd.

Inyang, N.E.U. (1993). Psychological theories of learning relevance to science teaching. In I.T. Eshiet (Ed.), Methodology of science teaching: Historical and conceptual approach. Abak: Belpot Nig. Company. 45-50.

Kersh, R.S. (1998). The adequacy of meaning and explanation for superiority of learning by independent discovery. Journal of Education and Psychology, 49, 282-292. 
Leinhardt, G. Seewald, A. \&. Engelra, B. (1997). Learning what is taught: sex difference in instructions: Journal of Educational Psychology, 60(24), 90.

Mayer, R.E. (2003). Learning and instructional. New Jersey: Pearson Education Inc.

Nicholas, E.D. (1986). Comparison of two approaches of teaching of selected topics in plane geometry. U.S.A.: University of Illinois.

Nwagbo, C. (1999). Effects of guided-discovery and expository teaching methods on the attitudes towards biology of students of with different levels of scientific literacy. Journal of the Science Teachers Association of Nigeria, (STAN), 36(1\&2), 43-51.

Onyejiaku, F.O. (1987). Technique of effective study. A manual for students in schools, colleges and universities. Calabar: Wusen Press Ltd.

Onwioduokit, F.A. \& Akinbobola, A.O. (2005). Effects of pictorial and written advance organizers on students' achievement in senior secondary school physics. Journal of the Science Teachers Association of Nigeria, 40(1\&2), 109-116.

Omwirhiren, E.M. (2002). The effect of guided discovery and traditional methods on the achievement of SSCE students in the chemical energetics. African Journal of Research in Education, 2(1\&2),21-24.

Ugwuanyi, J.U. (1998). Effects of guided discovery and expository teaching methods on students' achievement in physics in selected secondary schools in Nsukka, Enugu State, Nigeria. Nigerian Journal of Technical Education, 15(1), 167-171.

Urevbu, A.O. (1990). Methodology of Science teaching. Benin City: Juland Educational Publisher. 